\title{
Early Childhood Special Education: Insights from Educators and Families
}

\author{
Marie Tejero Hughes** \& Diana Martinez Valle-Riestra* \\ **University of Illinois at Chicago, College of Education \\ 1040 W Harrison Street MC 147, Chicago, Illinois 60607, United States \\ Tel: 1-312-413-1623 E-mail: marieth@uic.edu \\ *Florida International University, College of Education \\ 11200 SW 8th Street, ZEB Building, Miami, Florida 33199, United States \\ E-mail: riestrad@fiu.edu
}

Received: March 19, 2012 Accepted: April 7, 2012 Published: April 11, 2012

doi:10.5296/ije.v4i2.1534 URL: http://dx.doi.org/10.5296/ije.v4i2.1534

\begin{abstract}
Programs and services designed to meet the needs of young children with disabilities have increased substantially in recent years, often times without evaluating how effective the programs and services are at meeting the needs of children and families. This study sought to investigate how principals, teachers, and parents perceived how Early Childhood Special Education (ECSE) programs across 31 schools in a large, urban city in the United States (US) meet the needs of young children and their families. Thirty principals, 45 teachers, and 301 families participated in the investigation. Overall, all stakeholders identified the programs' structure, personnel, and home to school connections as strengths. They also believed that ECSE programs were an appropriate place for young children with disabilities. Families and teachers indicated satisfaction with the frequency of communication; however, both families and principals still wanted to see an increase in communication between home and school. Areas needing improvement included critical elements needed in ECSE programs related to human resources, increased funding, and appropriate adult-child ratios. Implications for practice are discussed.
\end{abstract}

Keywords: early childhood; special education; family; students with disabilities 


\section{Introduction}

Although most children served by special education programs in the United States (U.S.) are between the ages of six and 17, young children with disabilities are being identified with increasing frequency. Meeting the education needs of this population is a priority for the U.S. government, departments of education, and universities as seen in the U.S. government's commitment to a variety of initiatives that enhance the capacity of states, local educational agencies, and service providers to locate, identify, assess, and meet the needs of all children (i.e., "Good Start, Grow Start") (USDOE, 2002). With the increase of children with disabilities served through early childhood special education (ECSE) programs and services, more focus needs to be directed at evaluating the quality and effectiveness of early childhood practices in meeting the needs of young children with disabilities and their families (Dunst \& Trivette, 2009). According to Miller (1992), "service development undertaken in reactionary haste to meet legislative mandates may disregard the long-standing wisdom of our field and result in the continuation of fragmented program practices that offer little in the search for integrity of service delivery in early intervention" (Miller, 1992, p. 324).

The recognition of the importance of ECSE programs has been noted and shaped by history, legislation, research, and our views of child development. Quality in programs have been noted to run along a continuum focusing on classroom dynamics and interactions, classroom structure, staffing characteristics, professional development, administration and support services, and parent involvement (Buysee \& Hollingsworth, 2009). Exemplary ECSE programs should be integrated, comprehensive, normalized, adaptable, peer and family referenced, and outcome-based in addition to delivering high quality services and providing supports to children and their families (Sandall, Hemmeter, Smith, \& McLean, 2005). According to the Division of Early Child's (DEC) Recommended Practices (Sandall, Hemmeter, Smith, \& McLean, 2005), high quality in programs in reference to services must be stressed since these programs can make a positive difference in the development and lives of young children and their families. Strong emphasis should also be placed on the process of learning and development, and not just the end products; developing a universally designed curriculum framework that is flexible and comprehensive; working collaboratively with families; and embrace the practice of heterogeneous grouping that meets a variety of ability levels and individual needs (DEC, 2007). Furthermore, teacher-children interactions should promote and encourage two-way communication and provide opportunities for young children with disabilities to express their feelings, interests, and concerns. Other critical components of ECSE programs include having a competent and capable staff and having adequate administrative support.

Within these ECSE programs developmentally appropriate practices have been advocated for young children with disabilities based on the recognition that early experiences and later outcomes are linked (Sandall, Hemmeter, Smith, \& McLean, 2005). These practices should ultimately encourage a close match between the program, the family, and the child in order for the unique needs of all to be met. A developmentally appropriate curriculum would focus on the process of how children learn within the classroom; construct activities that are both age appropriate and individually appropriate, and are relevant and concrete to the 
children; and promote grouping formats that embrace a wide selection of abilities (DEC, 2007). Furthermore, developmentally appropriate programs identify, accept, and respect the values and diversity of families and children by encouraging the types of interactions that promote a shared sense of responsibility and collaboration with professionals and service providers (Trivette \& Dunst, 2000). For true collaboration to exist, "professionals have a significant responsibility to share all information in a way that matches the family's style of understanding and processing information" (Trivette \& Dunst, 2000, p. 41-42).

One of the hallmarks in the field of ECSE has been focusing not solely on the needs of the child and but focusing on both the child and his/her family (Turnbull, Turnbull, Erwin, Soodak, \& Shogren, 2010). The relationship between home and school is a critical component to providing quality educational services for young children (DEC, 2007), since children spend the majority of the time within a family unit. Families are the primary social systems whereby children develop as individuals and increased levels of family involvement can positively influence developmental progress in children (Bruder, 2010; Dunst, Trivette, \& Hamby, 2008).). Resources and supports that are provided in an ECSE program need to be family-centered "so family-based practices will have the child, the parent, and family strengthening and competency-enhancing consequences" (Trivette \& Dunst, 2000, p.39).

The majority of families with children with disabilities in the U.S. will become involved in ECSE programs and services when a variety of services are provided to assist them in adjusting to the challenges of raising their child. Establishing family members as "partners", "protectors" and "advocators" for their children is encouraged and reflected in our legislative mandates, because they make critical decisions about services that will lead to the achievement of goals that are most beneficial to their child and to themselves (Leviton, Mueller, \& Kauffman, 1992). Thus, the family's perspective on the effectiveness of services provided to their child with disability is essential in addition to the valuable information families provide about themselves and their child.

Due to the challenges in providing appropriate services to young children with disabilities, this study focused on how principals, teachers, and parents felt about how ECSE programs and services were meeting the needs of young children and their families. More specifically, we sought to understand principals, teachers, and parents' perceptions of ECSE programs across 31 elementary schools in a large, urban city in the U.S. including strengths and areas of needed improvement. The inclusion of multiple stakeholders and the use of interviews and surveys in the study provided an opportunity to examine the perceptions of key professionals and parents in the education of young children with disabilities.

\section{Method}

\subsection{Setting}

The study was conducted in a large, urban city that is composed of a highly diverse student population (48\% White; 35\% Black, non-Hispanic; 14\% Hispanic; 3\% other minority groups). The school district in this city has had a long history of offering a variety of ECSE services and programs to young children with disabilities and their families, and the programs 
are currently in a variety of schools and classrooms throughout the entire school district. For this study, we specifically focused on ECSE full-day programs (students attending preschool classes for at least 6 hours a day) serving children with high-incidence disability (e.g., developmental delays, language delays) ages 3 to 5. The classroom instruction was based on recommended DEC practices. The programs include: family education (e.g., session on storybook reading), support (e.g., parent to parent organization), and assistance (e.g., applying for free/reduce lunch support); receptive and expressive language activities; multi-sensory stimulation; cognitive and pre-academic development; social skills training; behavior management; and teaching appropriate play with toys.

Young children with disabilities are provided services in 57 classrooms at 31 elementary schools throughout the school district. Class sizes vary considerably from a minimum of seven children in one class to a maximum of 16 children in three classes. At the time of the study, most of the children who were provided with services were eligible as Developmentally Delayed (52\%) or Speech/Language Delayed (40\%).

\subsection{Participants}

\subsubsection{Principals}

All school principals ( $\mathrm{n}=31$ ) who had ECSE full-day programs at their school were asked to participate in a telephone interview in which all but one participated. The principals have an average of 8.1 years of administrative experience and averaged 3.4 years as principal of their current school. Furthermore, the principals reported that the ECSE program had been at their school for an average of five years, and that they had 1.4 years of experience working with an ECSE program at a previous school.

\subsubsection{Teachers}

All teachers in the ECSE full-day programs were hand delivered a survey by the Exceptional Education Specialist at their school. Forty-five teachers (79\%) completed and returned the survey. The majority of the teachers are female $(n=43)$ with $58 \%$ of the teachers indicating having a Bachelor's degree and 42\% having an advance degree. Most of the teachers were certified in at least one area of special education (e.g., learning disabilities). However, only $33 \%$ of the teachers specialized in young children with disabilities and only $20 \%$ of teachers were specialized in early childhood. The teachers had an average of 9.9 years of teaching experience of which 3.7 years were in an ECSE program.

\subsubsection{Families}

All families with children currently enrolled in one of the 31 ECSE full-day programs were mailed a survey. A total of 301 surveys (44\%) were completed and returned by the families. Sixty-three percent reported that their child had been in an ECSE program one-year or less. The majority (67\%) indicated that their child had a speech/language delay and $14 \%$ of the parents had a child with a developmental delay. The remaining families reported that their child had another type of disability (e.g., autism), with no category comprising more than $3 \%$ of the sample. No significant differences were noted between type of disability and length of 
time in the program.

\subsection{Measures}

\subsubsection{Development of instruments}

The instruments (interview and surveys) used were developed by the researchers in collaboration with school district personnel to achieve the study's goal of determining the perceptions of principals, teachers, and families and experiences they had with ECSE programs and services addressing the needs of young children with high-incidence disabilities. District guidelines placed certain constraints on the researchers in the development of the instruments including length, content, and issues surrounding confidentiality of respondents. At the request of the school district, principals were the only group interviewed via the telephone while teachers and families completed a survey.

All items on each instrument were derived from three sources: classroom observations, district guidelines, and a focus group interview. The first step was to conduct classroom observations $(n=6)$ to familiarize the researchers with the structure of these classrooms and the children. During the observations, the researchers took notes in the followings areas: classroom structure and set-up, daily schedules and activities, behavior management plan, materials and supplies, modes of home/school communication, and key components of the programs.

The school district provided the researchers with guidelines and descriptions of key components of the programs. A focus group interview was conducted at the school district's main office with teachers teaching in these classrooms. The group discussion consisted of questions about classroom programming and curriculum, support services, and home/school communication. This discussion provided participants with an opportunity to express their views and opinions and exchange ideas with other participants in the session. The focus group interview was structured and conducted based on the recommended procedures provided by Vaughn, Schumm, and Sinagub (1996). The final step involved conducting a pretest of the instruments with key personnel in the school district. The primary purpose of the pretest was to determine the clarity and consistency of responses within interview and survey questions.

\subsubsection{Principal telephone interview}

A telephone interview was developed to determine principals' perceptions of the ECSE program and services at their school including strengths and areas of needed improvement. Each interview consisted of six open-ended questions with probes of which the following is a sample: Please describe the ECSE program in your school; Identify and describe some strengths you see in the program at your school (e.g., facilitators); and Identify and describe areas in which you would like to see improvement for the program (e.g., barriers, inhibitors). Each interview lasted approximately 20 minutes with the interviewer taking notes and including salient quotations 


\subsubsection{Teacher survey}

The teacher survey consisted of 15 items, which required the teachers to rate components of the program using a four point Likert-type scale ( $1=$ strongly disagreed, $4=$ strongly agreed). A sample of items in this section included: This is an appropriate placement for the majority of children in my class; I am provided with sufficient aide/paraprofessional support; and Resources are available to meet the needs of the children in my class. In addition, teachers were asked five questions, which focused on the frequency and types of communication they had with parents (e.g., How often do you communicate with parents about their child's progress?). The Cronbach alpha for the survey was calculated at .75 . The survey concluded with an open-ended question requesting additional comments about their class.

\subsubsection{Family survey}

The family survey consisted of seven questions that focused on the types and frequency of communication parents had had with the teacher (e.g., How often do you and the teacher communicate about activities you can do at home with your child?). In addition, families were asked to respond to 12 Likert-type items (1=strongly disagreed, 4=strongly agreed), which had them rate different program components. Families were presented with items such as: I believe the class activities are appropriate for meeting the needs of my child; I am comfortable doing activities the teacher sends home with my child; and I believe my child's teacher is trained to meet the needs of my child. The Cronbach alpha for the parent survey was .95. The survey also included an open-ended question that asked parents to share any additional comments about their child's program.

\subsection{Data Analysis}

Data from the interviews and open-ended survey questions were gathered and coded using qualitative methodology (Anfara, Brown, \& Mangione, 2002; Miles \& Huberman, 1994; Patton, 2002). As suggested by Miles and Huberman (1994), three flows of analysis were applied for summarizing the data in the interviews and open-ended survey responses. The first flow of analysis involved two researchers independently summarizing the written interview data. Key themes were identified and the researchers met to discuss their findings. The second flow of analysis included the development of data summaries on each theme. This included written summaries of key topics (e.g., key components of an ECSE program). These data summaries were presented to the research team and findings were negotiated using the group mind process and specific categories were developed (Corbin \& Strauss, 2007). Rules were revised as needed and all salient phrases and sentences were read to insure they were placed in the appropriate theme. The third flow of analysis involved drawing conclusions and verifying findings. Contradictory evidence was examined and firmly established conclusions reported. Findings were summarized to reflect the major themes that emerged in the analysis supported by representative quotations. Furthermore, descriptive statistics were used to analyze the Likert-type items on the teacher and parent surveys. 


\section{Results}

Careful examination of the data revealed that across stakeholder groups there was consistency in regard to program strengths and areas needing improvement. Overall, principals, teachers, and families were satisfied with different aspects of the ECSE programs as noted in Tables 1 and 2. The data have been collapsed across stakeholder groups to highlight the salient issues that were raised and further supported with representative quotations by the research participants.

\subsection{Positive Perceptions}

\subsubsection{Meeting the needs of children}

A primary strength cited by all three stakeholder groups was the positive influence ECSE programs and services had on children with disabilities. Accordingly, $63 \%$ of the principals emphasized the importance of the programs and reported that they were a positive and necessary component of the school's educational services. Principals also emphasized the impact that ECSE programs have on the language development, social skills, and behavior of young children with disabilities. One principal reported, "I think it is great that people have finally realized that children should be treated at a younger age. It makes a difference." While another principal stated, "Observe these classes at the beginning of each day. They will make your day. I think these types of programs really help students improve in areas they are lacking."

Many of the teachers indicated that they were satisfied with their program and their job as highlighted by the following quotes, "The children show a great deal of improvement by the end of the school year. It is a wonderful experience for teachers, parents, and students" and "The ECSE program is a nicely designed program, with appropriate workshops/strategies offered to the teacher." Additionally, teachers reported high levels of satisfaction on the survey with several aspects of the programs including that the children were aware of the classroom's daily schedule (3.82), and believed most of the children in their class were appropriately placed (3.49) (see Table 1).

Table 1: Teachers' feedback $(n=45)$

\begin{tabular}{l|c|c}
\hline Statement & $M$ & $S D$ \\
\hline Appropriate placement for children & 3.49 & 0.63 \\
Aide knowledgeable about exceptional children & 3.45 & 0.73 \\
Satisfied with communication frequency & 3.28 & 0.75 \\
Topics for workshops are relevant & 3.27 & 0.69 \\
Social workers assist with children's families & 3.27 & 0.72 \\
Provide activities for families & 3.20 & 0.63 \\
Monthly allocation sufficient to purchase materials & 3.20 & 0.84 \\
Administrators' support & 3.20 & 0.97 \\
Provided with sufficient aide support & 3.18 & 0.94 \\
School provides assistance upon request & 3.14 & 0.91 \\
Sufficient space for learning centers & 3.07 & 0.89 \\
Attend early childhood special education workshops & 3.04 & 0.88 \\
Resources meet needs of children & 2.78 & 0.97 \\
Child-teacher ratio allows the needs of all children to be met & 2.48 & 1.15 \\
Materials are replaced as needed & 1.96 & 1.02 \\
\hline
\end{tabular}


Note: $1=$ strongly disagree; $4=$ strongly agree

Overall, families would recommend the programs to other parents (3.79), were satisfied with the child's program (3.73), and felt that their child's program was an appropriate placement for their child (3.71) (see Table 2). Families were satisfied with the progress their child had made while enrolled in the program especially in the areas of speech and language, and social and motor development. As one parent wrote, "I have been very pleased with our son's progress over the past six months. He has improved significantly in language and social skills." Another parent stated, "Since my child has been in the program I have seen so much improvement."

Table 2: Parents' satisfaction and perceptions $(n=301)$

\begin{tabular}{l|c|c}
\hline Statement & $M$ & $S D$ \\
\hline Recommend program & 3.79 & .64 \\
Satisfied with program & 3.73 & .71 \\
Appropriate placement for my child & 3.71 & .69 \\
Comfortable with activities sent home & 3.71 & .73 \\
Activities are appropriate for my child & 3.62 & .73 \\
Teacher trained to meet child's need & 3.64 & .68 \\
Aide knowledgeable about my child & 3.64 & .73 \\
Activities encourage child's independence & 3.61 & .74 \\
Familiar with teacher's classroom management & 3.59 & .79 \\
Testing results are shared with me & 3.59 & .84 \\
Satisfied with communication frequency & 3.55 & .84 \\
Familiar with activities in classroom & 3.54 & .76 \\
\hline
\end{tabular}

Note: $\quad 1=$ strongly disagree; $4=$ strongly agree

\subsubsection{Program personnel}

Principals also felt very strongly about the quality of the instructional staff in the programs. Eighty-three percent of the principals reported that their teachers were the key to their program's success. Many of the principals echoed the comments of this one, "Teachers are our biggest strength. They have lots of initiative and energy. These teachers have received good training which allowed them to provide these kids with the best learning methods."

Most of the teachers (89\%) reported that the paraprofessional assigned to their classroom was knowledgeable about working with children with exceptional needs. However, teachers did state that further training of paraprofessionals was needed before they entered the classroom. As one teacher noted, "They need to be required to take classes on children's disabilities, behavior management, and toileting skills."

Families indicated their satisfaction with their child's program personnel by noting the quality and professionalism of the staff. "Overall, I'm very satisfied with [the] ECSE program, it's the best. Your teachers deserve this credit because without them our kids wouldn't achieve as much as they do. My daughter loves her teachers. Thumbs up to all your Pre-K teachers and assistants" composed a satisfied parent. Another parent stated, "I am very pleased with the program my son has been placed in. The teachers are wonderful, and I already see a change in my son's speaking. I don't know what I would have done without 
this program."

\subsubsection{Home and school connections}

Another commonly cited strength of the programs was its emphasis on parent communication with $44 \%$ of the principals indicating that home/school connections were a particular strength. Principals commented in this way, "We have regular newsletters that parents receive each week. Also the parents receive constant information on parent involvement from the teachers" and "A major component of our program is family involvement. The teachers interact with the parents constantly. Our program also involves home visits. The teachers and the therapist go to the homes of each one of the 14 students we presently have."

The majority of teachers were satisfied with the frequency of communication they have with their children's parents (3.28) and provided activities for families to do with their children at home (3.20) (see Table 1). Fifty-one percent of teachers said that they communicated with families about their child's progress and $58 \%$ communicated about the child's behavior in the classroom on a daily basis. In addition, teachers indicated that on a weekly basis they discussed activities with parents that can be done at home (42\%). The most frequently identified modes of communication emphasized by teacher survey respondents were home visits (98\%), telephone calls (91\%), and newsletters (87\%).

Generally, families were satisfied with the frequency of communication with their child's teacher (3.55) and felt comfortable with the activities the teacher sends home (3.71) (see Table 2). "The teacher is wonderful with the kids and has always been available to listen to my concerns about J. and offers useful advice." Forty-four percent of parents indicated that they communicated with the teacher about their child's progress on a daily basis, and $41 \%$ discussed with the teacher their child's behavior during the school day. Furthermore, parents indicated that teachers provided them with activities to do with their child at home on a weekly basis $(43 \%)$ and that they visited their child's classroom (36\%). The most frequently identified modes of communication reported by parents on the survey were daily progress/behavior reports (72\%), home visits (61\%), and newsletters (60\%). Moreover, parents indicated that their preferred mode of communication was the daily progress/behavior reports $(53 \%)$.

Although families indicated satisfaction with the frequency of communication, some still reported wanting an increase in communication between home/school. As the following two parents reported, "We would appreciate better communication with the teacher on the activities in the classroom and our daughter's progress in the program. Also, we would like to know how to implement activities in the home" and "We would like to have more communication with our son's teacher. Our son has been in this program for almost six months and there is no communication between the teacher and myself."

\subsection{Areas Needing Improvement}

\subsubsection{Program supports}


An area of concern reported by principals and teachers focused on critical elements needed in place for program success particularly in the area of human resources. Although principals were positive about the quality and professionalism of classroom teachers, $57 \%$ indicated concerns about other areas of staffing. Some principals indicated the need for more support staff (e.g., family counselors, speech therapists) while others registered concerns about the quality of the substitute pool for handling the needs of this population of children. A principal commented, "The few times that the ECSE program's aide has been out, it has been impossible to find a substitute aide. This creates a problem because it is very hard for the teacher to attend to eleven children at a time. The county should train a group of aides to be on call." In addition, $30 \%$ of principals indicated that additional program areas were in need of improvement including more informational sessions for families and better procedures for transition into kindergarten.

Several teachers stressed the need for school sites and administrators to be prepared for new ECSE programs being implemented at their schools. The following quote highlights this need, "The school needs to be prepared for us. They weren't ready. There was a classroom prepared. That was it. Maybe in the future, we can train some of the administration as to what the needs are going to be."

\subsubsection{Funding and resources}

There was general consensus among principals and teachers that funding for the programs put constraints on the school budget. Seventy-seven percent of the principals indicated that the budget was a major concern. Related to budget considerations was the issue of resources with over $70 \%$ of the principals raising concerns about resources. Requests for additional resources were scattered, but included such items as computers and software, fieldtrips, classroom space, kitchen equipment, and health-related resources (e.g., immunizations). The majority of principals (67\%) indicated that dipping regularly into the school budget is necessary when replacing instructional materials. As this principal remarked, "The ECSE program has not replaced any materials, I wish they did. Today I am ordering materials from our school budget and I have to include them."

Overwhelmingly, teachers responded that the replacement of materials was an issue that concerned them. Teachers commented that replacing materials once used or broken was difficult due to the absence of systemic guidelines for how to order new materials as well as a lack of funds. Teachers' made the following statements, "I have a relatively new ECSE program and when they start-up they give you a good supply of your basics for block area, for housekeeping. For an early childhood program, I don't think they address the issue of when you run out" and "I do wish that we had more classroom space, materials were replenished instead of me having to buy toys, books and art supplies."

\subsubsection{Adult-child ratio}

The issue of ratios and appropriate coverage was a concern shared by all and noted as an area needing improvement. Many teachers reported dissatisfaction with the adult-child ratio in their classrooms and gave it a lower rating (2.48). Teachers were concerned that the larger 
classes were not allowing them to meet the needs of all the children. Teachers expressed this concern by stating, "I feel our classes are too large. There needs to be a cap on the class so we can better meet the needs of the children" and "With so many students, you just don't have the time to address all their needs."

Parents whose children were in larger classes also expressed their concern about adult-child ratio. As this parent expressed, "I feel children with special needs should be in smaller groups so that the teacher can concentrate and help them a little more one-on-one. The teacher can't when there is a dozen children with all different needs." Another parent made similar comments, "I feel that the preschool class is overcrowded. Ten preschoolers with one teacher in a small room is not a favorable atmosphere for learning."

\section{Discussion}

This study provides information regarding the perceptions of principals, teachers, and parents regarding how effective the ECSE programs for young children with disabilities in 31 schools are at meeting the needs of children and their families. Overall, all stakeholder groups identified the programs' structure, personnel, and home to school connections as major strengths. Stakeholders reported being satisfied with the overall quality of the programs, believed that the programs were an appropriate place for young children with disabilities, and would refer others to the services provided by the programs. These findings are consistent with other studies that have measured levels of satisfaction with early intervention services (e.g., Jinnah \& Walters, 2008). Principals, teachers, and parents also expressed the importance of providing children with disabilities with support services as early as possible and maintaining the continuity of these services over time as needed. This finding was also consistent with a theme (i.e., Families Must be Supported Earlier) that emerged in a study by Brotherson, Sheriff, and Milburn (2001) that children with disabilities and their families need to be provided the necessary supports early on. The importance of identifying children with disabilities during the early years and providing appropriate services to them and to their families is vital. The experiences children with disabilities have early on can establish the attitudes, behaviors, and competencies that later can contribute to patterns that are directly related to long-term school success (Alexander, Entwisle, \& Horsey, 1997).

Overall, stakeholders cited that the ECSE program at their schools was of high quality due in part to the home/school connections that are established. Families and teachers indicated satisfaction with the frequency of communication; however, both families and principals still wanted to see an increase in communication between the home and the school. Although teachers and principals perceive that they are making extensive efforts to establish effective patterns of communication with parents, still parents perceived the level and type of communication insufficient and wanted more. Family participation is critical since the child is embedded within the context of the family thereby the family has the potential to have the greatest impact and influence on a child's development. Furthermore, many in the field view early childhood programs as becoming extended families for children which further sheds light on the need to continue to support families and their chosen level of involvement, regardless of the degree of involvement. 
Principals and teachers identified the need for additional funding and resources as another area needing improvement. Funding shortages were identified as having an impact on the availability of resources, replacement of worn or broken materials, and personnel specifically support staff and a quality substitute pool. The issue of funding was also identified as a perceived challenge and a high priority item by principals in the study by Brotherson, Sheriff, and Milburn (2001). Other areas cited by stakeholders as needing improvement included providing more preparation for paraprofessionals working with young children with disabilities and allocating additional related services to children with disabilities (e.g., speech therapy, occupational therapy). As more young children are meeting eligibility criteria for a variety of programs and support services while the availability of funds continues to be limited and state budget are being significantly reduced. In light of this, many programs and schools are feeling the financial pressure and are trying to make creative and innovative changes to meet current and future demands.

The results of this study should be viewed in light of some methodological limitations. Although the construct of satisfaction is "volatile", and difficult to define and measure

(Schwartz \& Baer, 1991), assessing satisfaction and dissatisfaction is critical to providing better programs and services for children with disabilities and their families. In order to address the challenge of measuring satisfaction in our study, we employed the use of surveys that included a variety of questioning formats including open-ended questions. The use of open-ended questions provides opportunities for respondents to raise novel and unpredicted topics and furthermore encourage respondents to express their dissatisfaction (Perreault \& Leichner, 1993). A second limitation in our study was a lower than anticipated response rate from parents. Survey response rates are usually within the $60 \%$ to $75 \%$ range (Fowler, 1993) and we obtained on the parent survey a 44\%. This rate can be indicative of the constraints placed on us by the school district in not providing ways to contact non-respondents or conducting follow-up mailings. Furthermore, we were restricted by the school district from conducting interviews with parents due to confidentiality issues. However, we are confident that we obtained a fairly representative sample of parents based on demographic information provided by the school district. Social desirability may also be a source of bias in our study.

\section{Implications for Practice}

The results of this study have implications for practice and for professionals working with young children with high-incidence disabilities and their families. As much of the literature has suggested, establishing effective home to school connections is vital for children in ECSE programs. Although the language of U.S. federal laws reflect a more family-centered approach to services, mandate family involvement, and encourage families to become equal partners with professionals, many studies still show that family participation is limited (e.g., Rodger, Keen, Braithwaite, \& Cook, 2008). Participation may be limited due to a number of factors (e.g., parenting styles, parental beliefs and values, experience with the formal educational system). However, it is that much more of a challenge for service providers to find appropriate ways to develop strong connections between the home and the 
school by keeping parents informed and involved in all aspects of their child's education as well as recognizing that parents define involvement and participation in various ways. Professionals should be sensitive to the needs of all families by making adaptations when interacting with them. Professionals can facilitate these interactions by using a more personalized approach, having respectful verbal and non-verbal interactions, simplifying educational jargon, and ensuring parents comprehension of their rights and special education procedures (Harry, 2008). Moreover, professionals can consider inviting community liaisons to parent-teacher meetings, providing alternate forums for parents to voice their opinions and concerns (i.e., group meetings or family advisory boards), and meeting parents in "neutral" or family-friendly places in order to encourage more open and informal styles of communication (Parette \& Petch-Hogan, 2000).

Another issue raised primarily by principals and teachers was the availability of resources and the replacement of materials. While principals reported they had at least adequate resources, they also felt they needed to tap into outside funds to provide and replace the necessary instructional materials for the programs. Moreover, teachers commented that replacing materials once used or broken was difficult due to the absence of systemic guidelines for how to order new materials. Furthermore, principals, teachers, and families expressed a need for additional resources including computers, software, fieldtrips, and classroom space.

Due to this ongoing concern, a district-wide or state-wide plans need to be developed with the cooperation and insights of principals and teachers to ensure that all classrooms are equipped with the necessary materials and resources. Although most school districts provide an ample supply of classroom materials at the inception of a program, ongoing replacement and enhancement of resources is crucial throughout the existence of the program. Principals and teachers must be able to project future needs as well as keep abreast of the latest advancements in resources. Maintaining an ample supply of materials and resources is vital to the functioning of any classroom, but is it especially critical in early childhood classrooms where the curriculum focuses so strongly on a hands-on, exploratory approach to learning. Families could be included in replenishing supplies by sending home "need inventories" requesting for donations or specific supplies for the classroom. In addition, community partnerships and links should be established with local businesses and interested parties to facilitate the acquisition of needed supplies and materials for classrooms.

\section{References}

Alexander, K. L., Entwisle, D. R., \& Horsey, C. S. (1997). From first grade forward: Early foundations of high school dropout. Sociology of Education, 70(2), 87-107. http://dx.doi.org/10.2307/2673158

Anfara, V. A., Brown, K. M., \& Mangione, T. L. (2002). Qualitative analysis on stage: Making the research process more public. Educational Researcher, 31 (7), 28-38. http://dx.doi.org/10.3102/0013189X031007028 
Brotherson, M. J., Sheriff, G., \& Milburn, P. (2001). Elementary school principals and their needs and issues foe inclusive early childhood programs. Topics in Early Childhood Special Education, 21(1), 31-45. http://dx.doi.org/10.1177/027112140102100103

Bruder, M. B. (2010). Early Childhood Intervention: A Promise to Children and Families for Their Future. Exceptional Children, 76(3), 339-355.

Buysee, V., \& Hollingsworth, H. L. (2009). Program quality and early childhood inclusion: Recommendations for professional development. Topics in Early Childhood Special Education, 29, 119-128. http://dx.doi.org/10.1177/0271121409332233

Corbin, J., \& Strauss, A. (2007). Basics of qualitative research: Techniques and Procedures for Developing Grounded Theory and techniques. Newbury Park, CA: Sage.

DEC. (2007). Promoting positive outcomes for children with disabilities: Recommendations for curriculum, assessment, and program evaluation. Missoula, MT: Author.

Dunst, C. J., \& Trivette, C. M. (2009). Using research evidence to inform and evaluate early childhood intervention practices. Topics in Early Childhood Special Education, 29, 40-52. http://dx.doi.org/10.1177/0271121408329227

Dunst, C. J., Trivette, C. M., \& Hamby, D. (2008). Research synthesis and meta-analysis of studies of family centered practices. Asheville, NC: Winterberry Press.

Fowler, F. J. (1993). Survey research methods (2 ${ }^{\text {nd }}$ edition). Newbury Park, CA: Sage.

Harry, B. (2008).Collaboration with culturally and linguistically diverse families: Ideal versus reality. Exceptional Children, 74, 372-388.

Jinnah, H. A., \& Walters, L. H. (2008). Including parents in evaluation of a child development program: Relevance of parental involvement. Early Childhood Research and Practice, 10 (1). Retrieved from: http://ecrp.uiuc.edu/v10n1/jinnah.html (March 29, 2012).

Leviton, A., Mueller, M., \& Kauffman, C. (1992). The family-centered consultation model: Practical applications for professionals. Infants and Young Children, 4 (3), 1-8. http://dx.doi.org/10.1097/00001163-199201000-00003

Miles, M. B., \& Huberman, A. M. (1994). Qualitative data analysis (2 $2^{\text {nd }}$ ed.). Thousand Oaks, CA: Sage.

Miller, P. S. (1992). Linking theory to intervention practices with preschoolers and their families: Building program integrity. Journal of Early Intervention, 15, 315-325. http://dx.doi.org/10.1177/105381519101500401

Parette, H. P., \& Petch-Hogan, B. (2000). Approaching families: Facilitating culturally/linguistically diverse family involvement. Teaching Exceptional Children, 33(2), 4-10. 


\section{Macrothink}

Patton, M. Q. (2002). Qualitative evaluation and research methods. Thousand Oaks, CA: Sage.

Perreault, M., \& Leichner, P. (1993). Patient satisfaction with outpatient psychiatric services: Quantitative and qualitative assessments. Evaluation \& Program Planning, 16, 109-118. http://dx.doi.org/10.1016/0149-7189(93)90022-Z

Rodger, S., Keen, D., Braithwaite, M. \& Cook, S. (2008). Mothers' satisfaction with a home based early intervention programme for children with ASD. Journal of Applied $\begin{array}{llll}\text { Research in Intellectual Disabilities, 21, 174-182. } & \text {. }\end{array}$ http://dx.doi.org/10.1111/j.1468-3148.2007.00393.x

Sandall, S., Hemmeter, M. L., Smith, B. J., \& McLean, M. E. (2005). DEC recommended practices: A Comprehensive Guide. Longmont, CO: Sopris West.

Schwartz, I. S., \& Baer, D. (1991). Social validity assessment: Is current practice state-of-the-art? Journal of Applied Behavior Analysis, 24, 189-204. http://dx.doi.org/10.1901/jaba.1991.24-189

Trivette, C. M., \& Dunst, C. J. (2000). Recommended practices in family-based practices. In S. Sandall, M. E. McLean, \& B. J. Smith (Eds.), DEC recommended practices in early intervention/early childhood special education (pp. 39-46). Longmont, CO: Sopris West.

Turnbull, A.P., Turnbull, H.R., Erwin, E. J., Soodak, L. C. \& Shogren, K. A. (2010). Families, professionals, and exceptionality: Positive Outcomes through Partnership and Trust ( $\left.6^{\text {th }} e d\right)$. Upper Saddle River, NJ: Prentice-Hall.

USDOE (2002). Early childhood education plans under way. Community Update, 97 (May/June issue). Washington, DC: Author.

Vaughn, S., Schumm, J. S., \& Sinagub, J. (1996). Focus group interviews in psychology and education. Thousand Oakes, CA: Sage.

\section{Copyright Disclaimer}

Copyright reserved by the author(s).

This article is an open-access article distributed under the terms and conditions of the Creative Commons Attribution license (http://creativecommons.org/licenses/by/3.0/). 